\title{
A NEW InGaP/AlGaAs/GaAs COMPOSITE-EMITTER HETEROJUNCTION BIPOLAR TRANSISTORS
}

\author{
M. K. Tsai ${ }^{1}$, Y. W. Wu ${ }^{2}$, S. W. $\operatorname{Tan}^{2}$, M. Y. Chu ${ }^{2}$, W. T. Chen ${ }^{2}$, Y. J. Yang ${ }^{1}$, and W. S. Lour ${ }^{2, a}$ \\ 1 Department of Electrical Engineering, National Taiwan University, \\ Sec. 4, Roosevelt Road, Taipei, Taiwan, Republic of China. \\ ${ }^{2}$ Department of Electrical Engineering, National Taiwan-Ocean University, \\ 2 Peining Road, Keelung, Taiwan, Republic of China. \\ aCCorresponding author:wslo@mail.ntou.edu.tw
}

\section{ABSTRACT}

This paper reported a new composite-emitter heterojunction bipolar transistor (CEHBT) with a composite emitter formed of a $0.04 \mu \mathrm{m} \mathrm{In}_{0.5} \mathrm{Ga}_{0.5} \mathrm{P}$ bulk layer and a $0.06 \mu \mathrm{m} \mathrm{Al}_{0.45} \mathrm{Ga}_{0.55} \mathrm{As} / \mathrm{GaAs}$ digital graded superlattice (DGSL) layer. The CEHBT's exhibit a small collector-emitter offset voltage of $55 \mathrm{mV}$ and a base-emitter turn-on voltage of $0.87 \mathrm{~V}$, which is $0.4 \mathrm{~V}$ lower than that of $1.27 \mathrm{~V}$ of the InGaP/AlGaAs abrupt-emitter HBT. It is found that CEHBTs exhibits a current gain as high as 250 and is even enhanced to 385 when only a DGSL layer is used for passivation layer.

\section{INTRODUCTION}

The Npn heterojunction bipolar transistors (HBT's) have recently received intensive attention in both wireless and wired consumer products [1]. It has become one of the most important issues to reduce the base-emitter (B-E) turn-on voltage, $\mathrm{V}_{\mathrm{ON}(\mathrm{B}-\mathrm{E})}$, of HBT's. Typically, two main approaches in reducing $\mathrm{V}_{\mathrm{ON}(\mathrm{B}-\mathrm{E})}$ are 1 ) adoption of a narrower band-gap material for the base; and 2) elimination of the effect of the conduction and discontinuity at the B-E junction. InGaAs-based HBT's are first considered as candidates for the next-generation power-amplifier. However, InP technology is expensive and a large spike at the $\mathrm{B}-\mathrm{E}$ junction severely limits the reduction of $\mathrm{V}_{\mathrm{ON}(\mathrm{B}-\mathrm{E})}$ [2]. Another $\mathrm{p}$-InGaAsN-based HBTís reported are double-heterojunction ones. The blocking effect at the B-C heterojunction results in a high knee voltage. Furthermore, the expected reduction of $\mathrm{V}_{\mathrm{ON}(\mathrm{B}-\mathrm{E})}$ is usually not so significant due to increased $\Delta \mathrm{E}_{\mathrm{C}}[3]$.

In this work, we report the use of a composite emitter comprising an InGaP layer and a digital graded superlattice (DGSL) layer. The InGaP bulk layer functions as 1) hole confinement layer, 2) conduction-band transition layer between DGSL and narrow-gap GaAs cap layer, and 3) etching stop layer for well-controlled 
passivated devices with optimum passivation-layer thickness. Whereas, the DGSL layer forms a step-wise graded composition to smooth out the potential spike associated with the hetero-interface. Although numerous reports have demonstrated grading growth of $\mathrm{AlGaAs} / \mathrm{GaAs}$, it gives additional difficulties and complexities with MBE system. Moreover, this grading is not suitable for those material alloys mismatched each other. For MOCVD, changing material composition by adjusting the precursor flux may also cause reliability problems.

\section{EXPERIMENT}

Three different types of device are compared in this study: the InGaP/DGSL-passivated CEHBT, the DGSL-passivated CEHBT and the AlGaAs-passivated InGaP/AlGaAs HBT. Both the CEHBT"s employ the same device structure grown on a (100)-oriented GaAs substrate by MOCVD. As shown in Fig.1, the DGSL structure comprises four superlattice unit cells of four different barrier/well thicknesses $(10 / 40,20 / 30,30 / 20$ and $40 / 10$ up on base in sequence). Each of the four superlattice unit cells has a combination of 3 periods of $\mathrm{Al} 0.45 \mathrm{Ga} 0.55 \mathrm{As} / \mathrm{GaAs}$ quantum wells. The device structure for the InGaP/AlGaAs HBT is the same except that an $\mathrm{AlGaAs}$ bulk layer replaces the $\mathrm{Al} 0.45 \mathrm{Ga} 0.55 \mathrm{As} / \mathrm{GaAs}$ DGSL layer. A $0.1 \mu \mathrm{m}$ GaAs layer with carbon doped to $4 \times 10^{19} \mathrm{~cm}^{-3}$ and $0.5-\mu \mathrm{m} 5 \times 10^{16} \mathrm{~cm}^{-3}$ GaAs layer were employed as base and collector, resulting in a $\mathrm{V}_{\mathrm{EB}(\mathrm{BD})}=7 \mathrm{~V}, \mathrm{a} \mathrm{V}_{\mathrm{CB}(\mathrm{BD})}=17 \mathrm{~V}$ and $\mathrm{a} \mathrm{R}_{\mathrm{B}}=600 \Omega /$.

The calculated results (by transfer matrix method) under various $\mathrm{W}: \mathrm{B}$ conditions according to $\mathrm{Al}_{0.45} \mathrm{Ga}_{0.55} \mathrm{As} / \mathrm{GaAs} 3$-period quantum wells shows the lowest mini-band energy for electrons is $60 \mathrm{meV}$ for $W: B=1: 4,113 \mathrm{meV}$ for $W: B=2: 3,180 \mathrm{meV}$ for $W: B=3: 2$, and $260 \mathrm{meV}$ for $W: B=4: 1$,

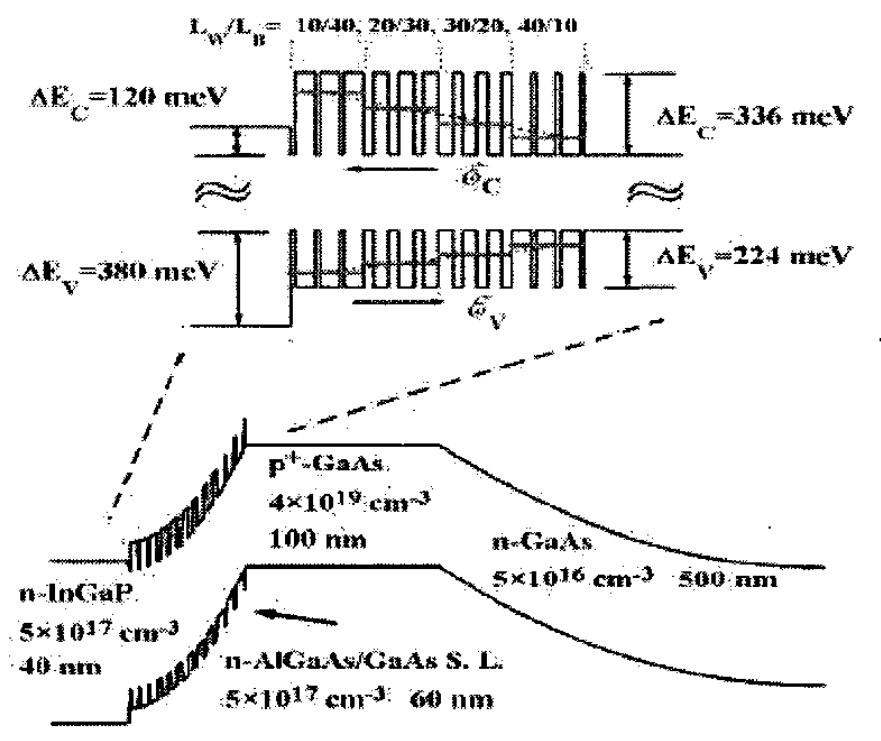

Fig. 1 The schematic band diagram of the InGaP/DGSL composite-emitter heterojunction bipolar transistor. 
respectively. It is evident that the DGSL layer forms a step-wise graded composition to smooth out the potential spike associated with the hetero-interface. The fabrication started with mesa isolation. The $\mathrm{Al}_{0.45} \mathrm{Ga}_{0.55} \mathrm{As} / \mathrm{GaAs}$ DGSL layer was etched by using $1 \mathrm{H}_{2} \mathrm{SO}_{4}: 1 \mathrm{H}_{2} \mathrm{O}_{2}: 8 \mathrm{H}_{2} \mathrm{O}$ solution at new CEHBT with structural parameters. a etching rate of $210 \AA / s$. Etching selectivity between GaAs (etched in $3 \mathrm{NH}_{4} \mathrm{OH}: 1 \mathrm{H}_{2} \mathrm{O}_{2}: 50 \mathrm{H}_{2} \mathrm{O}$ ) and $\mathrm{InGaP}$ (etched in $3 \mathrm{NH}_{4} \mathrm{OH}: 1 \mathrm{H}_{2} \mathrm{O}_{2}: 50 \mathrm{H}_{2} \mathrm{O}$ ) was employed throughout this work [4]. An HBT was formed to have a passivation layer composed of an InGaP layer and an $\mathrm{Al}_{0.45} \mathrm{Ga}_{0.55} \mathrm{As} / \mathrm{GaAs}$ DGSL layer. The InGaP layer in InGaP/DGSL-passivated CEHBT was then selectively etched away to form a DGSL-passivated CEHBT. An AlGaAs-passivated HBT was also fabricated for comparison.

\section{RESULTS AND DISCUSSION}

Figure 2 shows the common-emitter characteristics for the InGaP/DGSL- and DGSL-passivated CEHBT's. A small collect-emitter offset voltage of $55 \mathrm{mV}$ and knee voltage of $0.3 \mathrm{~V}$ at a collector current of $1 \mathrm{~mA}$ were obtained for both devices. These phenomena reveal that the DGSL structure really eliminates the spike resulting from $\Delta \mathrm{E}_{\mathrm{C}}$. In particular, the $\Delta \mathrm{E}_{\mathrm{C}}$ associated with $\mathrm{Al} 0.45 \mathrm{Ga} 0.55 \mathrm{As} / \mathrm{GaAs}$ is at least $336 \mathrm{meV}(120 \mathrm{meV}$ for InGaP/GaAs). Therefore, an InGaP layer really works well as transition layer and the offset voltage is mainly contributed to emitter-collector geometry difference.

Figure 3 shows the Gummel plots of InGaP/DGSL- and DGSL-passivated CEHBTís with $\mathrm{V}_{\mathrm{BC}}=0 \mathrm{~V}$. We firstly refer to the DGSL- and the AlGaAs-passivated devices. An important merit of the DGSL-passivated HBT is its VON(B-E) defined as VBE at which the collector current exceeds $1 \mu A$. The VON(B-E) of DGSL-passivated CEHBT is $0.87 \mathrm{~V}$, which is $0.4 \mathrm{~V}$ lower than the $1.27 \mathrm{~V}$ measured in an AlGaAs-passivated HBT over a wide rang of current level. However, the collector and base ideality factors for the DGSL-passivated CEHBT are 1.2 and 1.9, respectively. Clearly, this is resulted from the space charge region recombination current since grading emitter is implemented. We thus find the current gain of the DGSL-passivated CEHBT increases with the

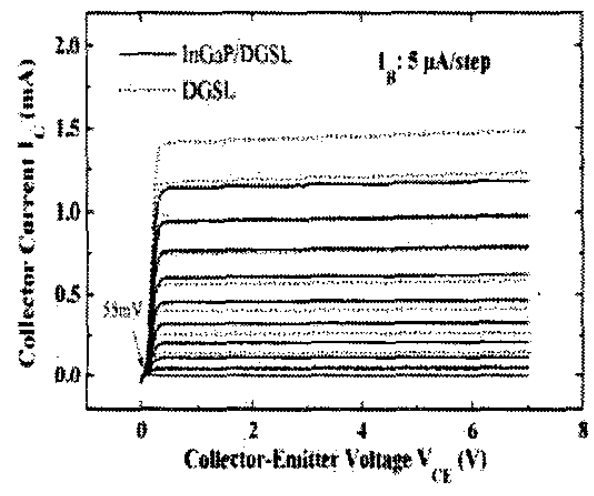

Fig. 2 Common-emitter current-voltage characteristics for the InGaP/DGSL- and DGSL-passivated CEHBT's.

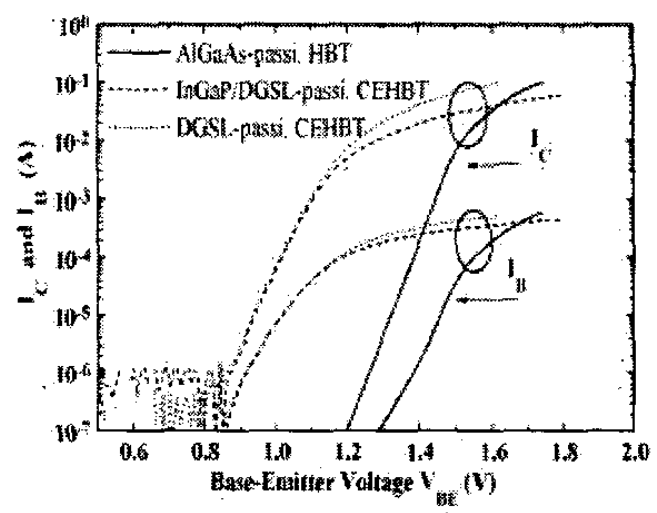

Fig. 3 The measured Gummel-plots for three types of passivated HBTs 
collector current and even reaches 385, which is higher than that of the AlGaAs-passivated HBT (250), as shown in Fig.4. We find that the existence of the InGaP does not change VON(B-E) (i.e., 0.86 and $0.87 \mathrm{~V}$ ). However, the InGaP/DGSL-passivated HBT exhibits a smaller current gain, indicating that optimized passivation-layer thickness is around $600 \AA$ by selectively removing the InGaP layer, as suggested in the authors' previous work [5].

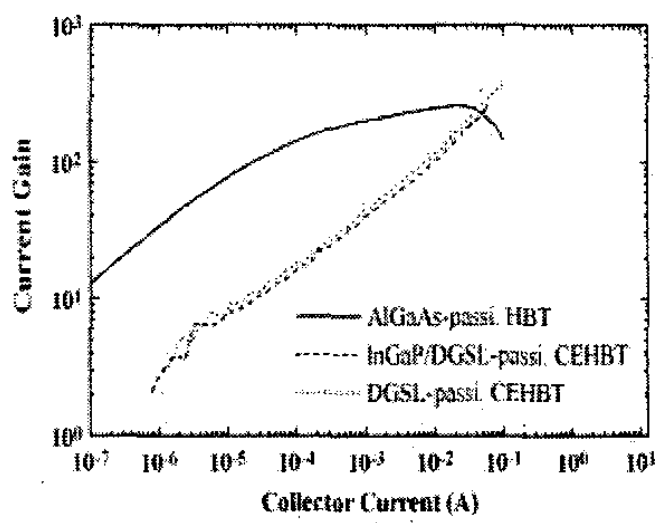

Fig. 4 The calculated current gains as a function of collector current for the fabricated devices.

\section{CONCLUSIONS}

We have demonstrated and analyzed a new InGaP/DGSL composite emitter for use in heterojunction bipolar transistors. The studied devices exhibit superior direct-current characteristics to those of conventional GaAs-based HBT's. Moreover, due to simplified growth control for both MBE and MOCVD, the DGSL technology is a promising alternative to the conventional grading growth method for the AlGaAs/GaAs lattice-matched material system and even if lattice-mismatched ones.

\section{ACKNOWLEDGEMENT}

This work is partly supported by National Science Council under the contract No. NSC 91-2215-E-019-001.

\section{REFERENCES}

1. N. Pan, J. Elliott, J. Knowles , D.P. Vu, K. Kishimoto , J.K. Twynam, H. Sato , M.T. Fresina and G.E. Stillman, IEEE Electron Device Lett. 19, 115 (1998).

2. K. Yang, J.C. Cowles, J.R. East and G.I. Haddad, IEEE Trans. Electron Devices 42, 1047 (1995).

3. N.Y. Li, P.C. Chang, A.G. Baca, X.M. Xie, P.R. Sharps and H.Q. Hou, Electronics Lett. 36, 81 (2000).

4. W.S. Lour, W.L. Chang, Y.M. Shih and W.C. Liu, IEEE Electron Device Lett. 20, 304 (1999).

5. W.S. Lour and J.L. Hsieh, Semicond. Sci. Technol. 13, 847 (1998). 